\title{
A Survey on License Plate Recognition Systems
}

\author{
Divya Gilly \\ Computer Science and Engineering Department \\ Karunya University
}

\begin{abstract}
License Plate Recognition (LPR) is a well known image processing technology. LPR system consists of four steps: capture the image from digital camera, pre-processing, character segmentation and character recognition. License plates are available in various styles and colors in various countries. Every country has their own license plate format. So each country develops the LPR system appropriate for the vehicle license plate format. Difficulties that the LPR systems face are the environmental and non-uniform outdoor illumination conditions. Therefore, most of the systems work under restricted environmental conditions like fixed illumination, limited vehicle speed, designated routes, and stationary backgrounds. Each LPR system use different combination of algorithms. From the papers being surveyed, it is realized that a good success rate of $93.7 \%$ is obtained by the combination of fuzzy logic for license plate detection and Self Organizing (SO) neural network for character recognition. Comparisons of different LPR systems are discussed in this paper.
\end{abstract}

\section{Keywords}

Image processing, License Plate Recognition, License Plate Detection, License Plate Segmentation, Optical Character Recognition .

\section{INTRODUCTION}

License plate numbers are being used to uniquely identify a vehicle. LPR system plays an important role in many applications like electronic payment system (toll payment [3] and parking fee payment), to find stolen cars [1], traffic surveillance. For example in parking, number plates are used to calculate the duration of the parking. When a vehicle enters the gate, license plate is automatically recognized and stored in database. On leaving, the license plate is recognized again and compared with the stored numbers in the database. The time difference is used for calculating the parking fee. LPR is convenient and cost efficient as it is automated.

\section{LICENSE PLATE RECOGNITION SYSTEM}

Fig.1 shows the block diagram of LPR system. Next section describes the types of algorithm used in each stage in different LPR systems.

\author{
Kumudha Raimond, PhD. \\ Computer Science and Engineering Department \\ Karunya University
}

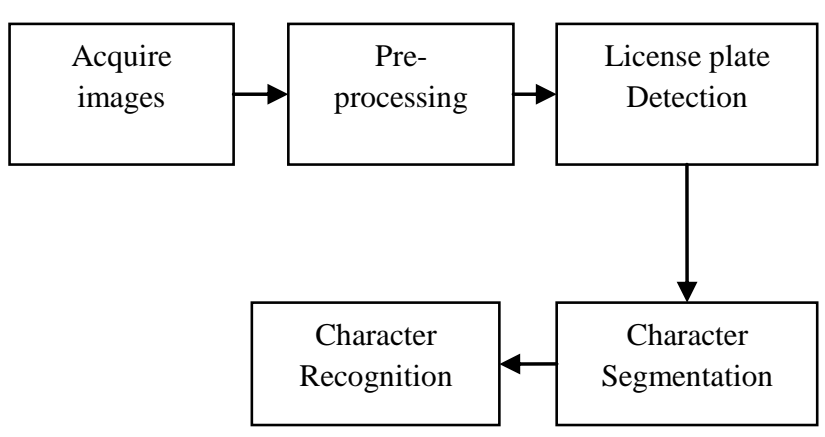

Fig 1. Block diagram of License Plate Recognition System

\subsection{PREPROCESSING}

Before the License Plate Detection (LPD) stage, several preprocessing techniques have to be performed to improve the quality of images, to remove shadows and to remove noises in the image. Pre-Processing stage is an aid to improve the LPD rate. Several pre-processing algorithms that have been encountered while researching the LPR systems are discussed in this section.

In [1], Otsu binarization method is used. The acquired image is segmented into several sub-regions. For each sub-region, threshold value is calculated. According to Anagnostopoulos et.al., [4], pre-processing is performed to detect the Region of Interest (ROI) even in the ambient illumination conditions. It is done using image masking, binarization with Sauvola method. In Sauvola method, locally adaptive thresholding is used to convert a gray scale image to a binary image. The value of threshold mainly depends on the local statistics like range, variance and surface fitting parameters. In the case of badly illuminated areas, calculated threshold value will be low.

According to Chang et al, [5], binarization is performed mainly for two purposes: to highlight characters and to suppress background. While doing the binarization some important information from the images will be lost, so they employed a variable thresholding technique proposed by Nakagawa and Rosenfeld [5]. In this technique, a local optimal threshold value is determined for each image pixel so as to avoid problem originating from non-uniform illumination. Although locally adaptive thresholding method cannot completely compensate the loss of information, it at least preserves the information that may be lost when using a constant binarization method.

In [6], a global threshold value is chosen instead of an adaptive one. To minimize the processing time, the original image is 
downsampled to 120 columns by preserving the original aspect ratio. G.Sun et al., in [7] divided the pre-processing task into luminance adjustment and image enhancement. These two tasks are achieved by changing luminance curve and top-hat transform respectively. Main advantage of gray scale top hat transform is that it enhances the hot region by differentiating the front and background while weakening the other regions at the same time. Fig. 2 shows the result of top-hat transform.

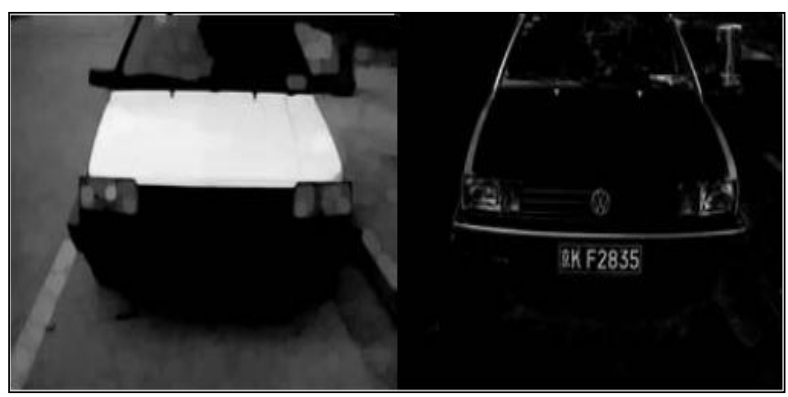

Fig 2. Result of top-hat transform [7]

According to T.Duan et.al., [9], pre-processing is performed to enrich the edge features. The algorithms used at this stage are graying, normalizing and histogram equalization. Histogram equalization is used to improve the contrast of image, which can be used to improve the results of edge detector. Locally adaptive thresholding is used for binarization.

In [11], image de-noising is applied to remove noises in the images. In this procedure, subtle fractures can be linked and tiny abrupt changes can be softened. The main aim of this technique is to prevent the destruction of image edges, to retain the image outline and lines as much as possible, increasing the contrast between the ROI and other regions. In [10], improved Bernsen algorithm is used to effectively remove the shadows in the image by converting it into a binary image. Improved Bernsen algorithm calculates two threshold values: threshold of the original image and the threshold value of the Gaussian filter applied image. Each pixel of the original image is compared with these threshold values to convert it to a binary image.

\subsection{LICENSE PLATE DETECTION}

LPs are located by means of horizontal and vertical projections through search window in [1]. If the LP is not found using the above method then the original image is inverted. Since LPs are located at the bottom part of the image, projection histograms are scanned from the bottom to the top so that the height of the LP can easily be identified. Fig. 3 shows the result of horizontal segmentation. After performing the horizontal segmentation, vertical projection is carried out. Fig. 4 shows the result of vertical segmentation. In [2], region with dense vertical edges is segmented as a candidate plate which is known as ROI. In the location procedure, vertical Sobel edge features are primarily extracted. Then a skeleton extraction algorithm on edge map is performed. There is a possibility that dense pixels are text region and isolated edge pixels are often noises. So density based region growing method is used to locate candidate LP regions. Fig. 5 shows the ROI location.

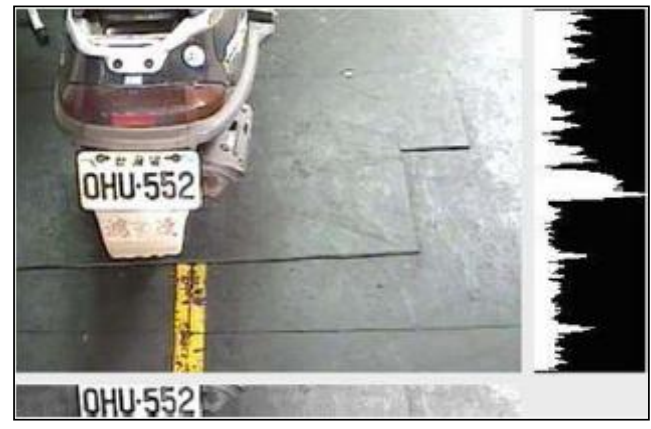

Fig 3. Horizontal segmentation [1]

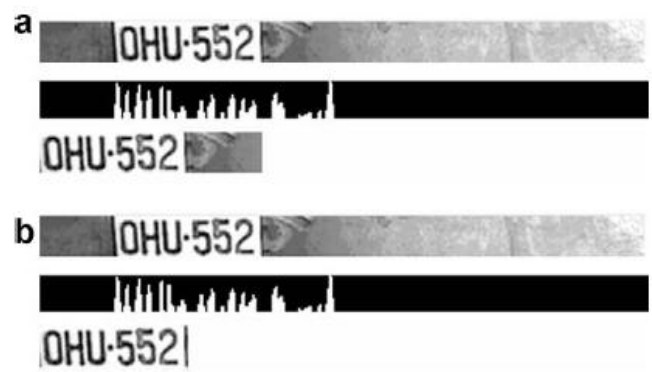

Fig 4 vertical segmentation (a) without search window (b) with search window [1] a

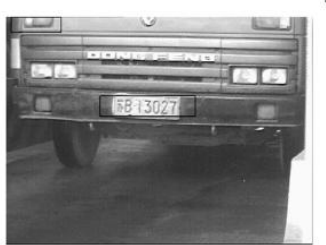

C

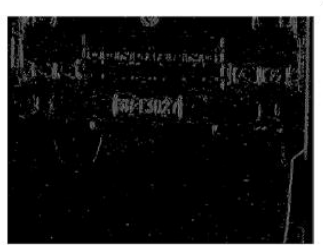

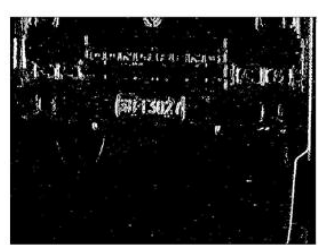

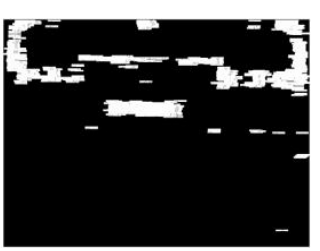

Fig 5. Illustration of ROI location (a) an LP image (b) Sobel edge detection result (c) edges skeleton (d) region after density based region growing method [2]

In [3], [10] and [4] Connected Component Labelling (CCL) is used for LPD. CCL scans the image and labels the pixels according to the pixel connectivity. There are two types of connectivity:-4 and 8 connectivity. In [3], a feature extraction algorithm is used to count the similar labels to distinguish it as a region. The region with maximum area is considered as a possible license plate region and this region is forwarded to the segmentation process. But in [10], two detection methods are performed. One is detection of white frame and another one is detection of black characters. White frame is detected using CCL technique and it is sensitive to the edges. So if the frame is broken, the LP cannot be located properly. To determine the candidate frames, aspect ratio of the LP, height and width of 
characters have to be known. Further, the penetration times through the midline of the large numerals in the LP is also calculated for candidate frame selection.

In [4], after the successful CCL on the binary image, measurements such as orientation, aspect ratio, Euler number for every binary object in the image are calculated. Criteria such as orientation $<35$ degrees, $2<$ aspect ratio $<6$ and Euler number $>3$ are considered as candidate plate regions in [4]. But this method does not guarantee that LP with dark background and white characters will be successfully detected.

In [5], fuzzy logic is used to locate LP. The author framed some rules to explain about the LP and gave some membership functions for fuzzy sets - "bright", "dark", "bright and dark sequence", "texture" and "yellowness" to obtain the horizontal and vertical plate positions. But this need is very sensitive to the LP color and brightness. It also takes longer processing time compared to conventional color based methods.

In [6], vertical edge detection method is utilized for locating the LP. So Robert's edge detector is used to emphasize the vertical edges. There will be many abrupt intensity changes but a cluster of 10-15 sharp intensity changes is considered as plate zone. Image is convolved with horizontally oriented rank-filter of $\mathrm{M} \times \mathrm{N}$ pixels. This leads to a bright-elongated spot of ellipsoidal shape in the plate's area. The last step is horizontal projection. Fig. 6 illustrates the LPD used in [6].
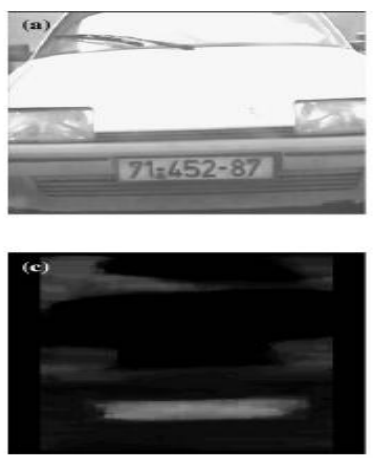
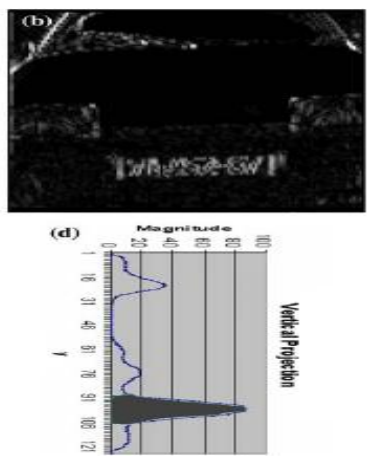

Fig 6. (a) original image (b) vertical edge map (c) rank filtered image (d) vertical projection [6]

In [11], after applying the Sobel edge detection method certain rules have been applied to locate the LP area. The first criterion is to find the column range of LP. Second step is to detect row range. After these steps, license plate will be obtained. So, to eliminate some candidate, the pseudo license plate aspect ratio of each candidate region is calculated. In [9], a combination of Hough transform and counter algorithm is applied to detect the LP region. First the counter algorithm is applied to detect the closed boundaries of objects. These counter lines are transformed to Hough coordinate to find interacted parallel lines that are considered as LP candidates. Fig. 7 shows the result of using the counter and Hough transform method. To filter out the candidate plates, the aspect ratio of the LP and the horizontal cross cuts are used. In the case of number of horizontal cross cuts for 1 row plate is in the range of 4 to 8 . For 2 row plate, it is in the range of 7 to 16 . Fig. 8 shows some sample cross cut results.

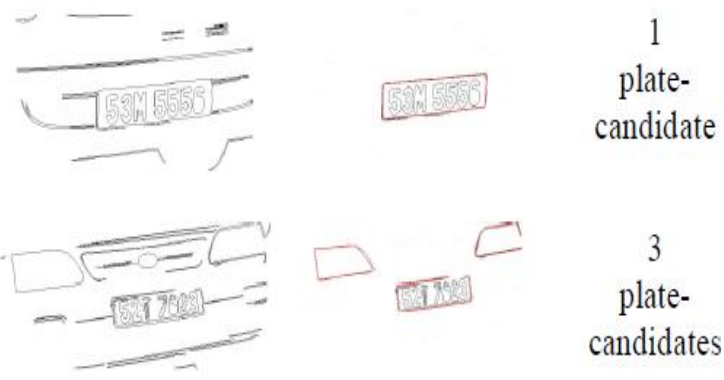

Fig. 7 Result of combination of Counter and Hough transform method [9]

\begin{tabular}{|c|c|l|}
\hline Plate-candidates & $\begin{array}{c}\text { Number } \\
\text { of objects }\end{array}$ & Result \\
\hline & 2 & Non-plate \\
\hline & 2 & Non-plate \\
\hline $53 \% 4893$ & 10 & Plate \\
\hline $\begin{array}{c}52 T \\
7013\end{array}$ & 4 & Plate \\
\hline
\end{tabular}

Fig 8. Sample results of horizontal cross cuts [9]

\subsection{SKEW CORRECTION}

It is not possible to take pictures without any tilt. So for successful recognition of license plate, tilt correction has to be performed after LPD. In [6], skew correction is performed using Randon Transform (RT). But this RT method has a large computation cost. So to reduce the cost, RT is replaced by faster Hough transform. Fig 9 shows the result of skew correction.

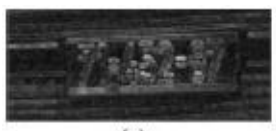

(a)

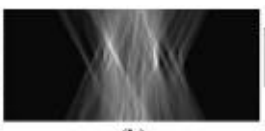

(b)

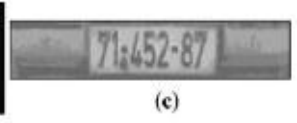

(c)
Fig 9. (a) Extended image strip (b) Randon transform space of (a) (c) Deskewed image strip (skew of $-3^{0}$ was detected) [6]

In [9], a new skew correction is developed with high speed of operation, high accuracy and simple structure. The left half of the image is scanned and the average height of white pixel is calculated, denoted as "leftaver". Then, the right half is scanned and "rightaver" is calculated. Slope is calculated:

$$
\text { Slope }=\frac{\text { leftaver }- \text { rightaver }}{n W i d t h / 2}
$$

Where nWidth is the width of the LP 
In [10], both the horizontal and vertical correction is done. Fig. 10 shows the result of tilt correction. In the case of horizontal correction, the large numerals are detected and the tilt angle between two central points of the numerals is found and the average tilt angle is calculated. Then the 2-D rotation is performed. For vertical correction, projective minimum is calculated.

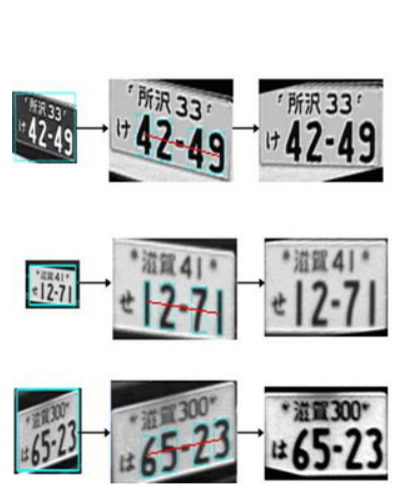

(a)

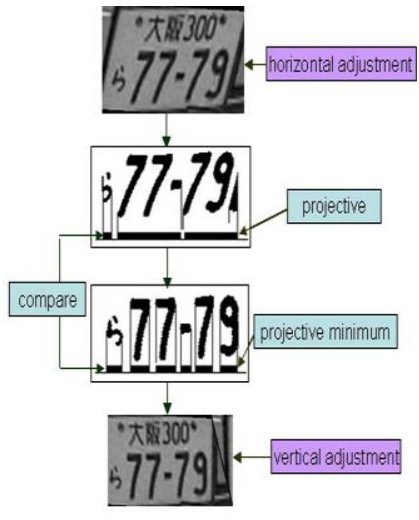

(b)
Fig 10. (a) Horizontal correction (b) Vertical correction [10]

\subsection{CHARACTER SEGMENTATION}

After locating the LP and skew correction, next step is the segmentation of characters. Character segmentation is the procedure of extracting the characters from the LP image. Almost all the papers that had been surveyed [1], [3] and [10] used horizontal and vertical projection to segment the characters. Fig. 11 shows the result of character segmentation used in [10]. In [8], vertical and horizontal scanning is used to dig out the characters. Vertical scanning will scan the image vertically from $[0,0]$ to [height, width] which is executed on column by column basis. Width between the first and last column is computed and each character is separated from the plate background and stored in separate array so that it is used for horizontal scanning. Horizontal scanning is performed to eradicate the extra upper and lower region from the image.

In [2], different methods are used for character segmentation. Firstly, a gray-level quantization and morphology analysis are performed to obtain the candidate characters. The size of "close" operator chosen was $(1,0.2 \times \mathrm{H})$ pixels in $\mathrm{X}$ and $\mathrm{Y}$ orientations where $\mathrm{H}$ represents the height of ROI. To improve the segmentation procedure, above mentioned method is combined with binarization method.

\subsection{CHARACTER RECOGNITION}

After segmenting the characters, the next step is character recognition. Almost all LPR systems are using different types of

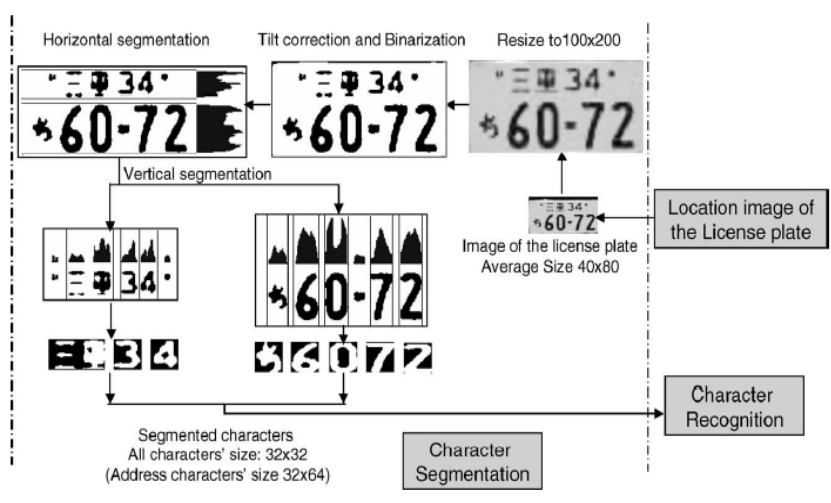

Fig 11. Flow chart of character segmentation [10]

Artificial Neural Network (ANN). SO neural networks based on Kohonen's self-organized feature maps is implemented in [5] to handle noisy, deformed, broken, or incomplete characters acquired from LPs that were bent and/or tilted with respect to the camera. This method focused on accuracy at the cost of increased complexity and execution speed. The success rate for character identification, in a large set of 1061 LPs in various viewpoints (combinations of angle and distance) is around 95.6\%. To avoid misclassification of similar character pairs (8, B), (0/D), and (O/D), Chang et.al. [5] pre-defined an ambiguity set that contains the pairs of them as classified characters. During character recognition, once an unknown character is classified as one of the characters in the ambiguity set, an additional minor comparison between the unknown character and the classified character is performed. The comparison then focused only on the non ambiguous parts (see Fig. 12).
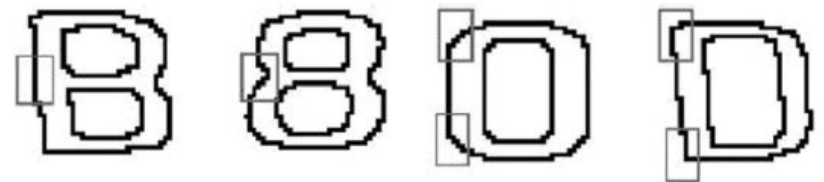

Fig 12. Disambiguous Parts of Characters [5]

Probabilistic Neural Networks (PNNs) are introduced in the neural network literature by Anagnostopoulos et al. [4]. These type of neural networks can be designed and trained faster, as the hidden-layer neurons are defined by the number of the training patterns and are only trained once. PNN for LPR is first introduced in an early version of an LPR system where two PNNs, i.e., one for alphabet recognition and the other for number recognition, are trained and tested. The recognition rates reported in the literature are very encouraging when PNNs are trained and tested in noisy, tilted, and degraded patterns. The Optical Character Recognition (OCR) system is a two layer PNN with a topology of 108-180-36 nodes, whose performance for entire plate recognition reached $89.1 \%$.

Huang et al. [1] uses back propagation neural network (BPNN) for recognizing characters. The 26 vertical and 50 horizontal projections of the normalized $26 \times 50$ pixel license plate image are fed into 76 input nodes of BPNN. This network also comprises of 85 hidden nodes and 6 output nodes. Most license 
plate characters are successfully recognized by BPNN. However, characters such as $\mathrm{B}$ and 8,1 and $\mathrm{I}, 8$ and $\mathrm{B}$, and $\mathrm{O}$ and $\mathrm{D}$ may be hard to distinguish using the neural network. The most significant difference between the characters $\mathrm{O}$ and $\mathrm{D}$ lies at their upper and lower left corners as shown in Fig. 13 a, b. A straight line is posted to the character as the base line to respectively accumulate the number of white pixels at the upper and lower left corners. The recognition rate is $97.3 \%$.
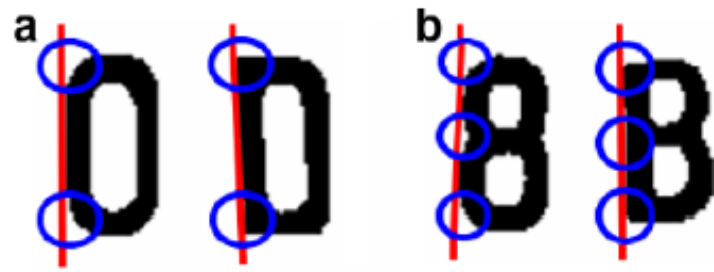

Fig 13. Features of Similar Characters [1]

In [10], Support Vector Machine (SVM) is used for character recognition. Before training and testing, features are extracted using Local-Direction Contributivity Density (L-DCD) and Global-Direction Contributivity Density (G-DCD). Compared to neural networks, SVM has less misclassification rate.

In [8], template matching method is used for character recognition. Each segmented character is matched with the stored template. Priority is assigned for each template. When matching is performed, first the highest priority template is compared and if a match occurs the lowest priority templates are ignored. Number templates are assigned higher priorities because chances of occurrences of alphabets are less than the numbers. Caner et al. in [3] used a Self Organizing Map (SOM) neural network to identify the characters. An ordinary SOM has the following two layers: 1) an input layer and 2) a computation layer. The computation layer has the processing units. The weight matrix of the SOM is calculated during the learning phase. The hardware designed calculates the hamming distance between the weight matrix of each neuron and the input image and makes a decision on the output character. The recognition rate is $90.93 \%$.

In [6], two types of template matrix or feature vectors are extracted: Object Thinned Representation (OTR) and Characteristics Background Spots (CBS). OTR represents the character shape. CBS reflect the map of the image background within character bounding box. Postpocessor is responsible for refining recognition results by making use of the specific LP context.

\section{COMPARISON}

Table 1 shows the comparison between different LPR systems being surveyed. Table 2 shows the comparison of different LPD systems.

\section{CONCLUSION}

The objective of this paper is to review about different LPR systems. Some LPR systems can work under uncontrolled environment but some in restricted environment. In the recognition phase compared to the SVM and template matching method, neural networks is having high misclassification rate. From the papers surveyed, it is realized that the combination of search window method and artificial neural network has given best results but it is mainly applied to motorcycles. For the case of cars, Fuzzy logic and SO neural network has given the best result.

\section{REFERENCES}

[1] Y. P. Huang, C. H. Chen, Y. T. Chang, and F. E. Sandnes, "An intelligent strategy for checking the annual inspection status of motorcycles based on license plate recognition," Expert Syst. Appl., vol. 36, no. 5, pp. 9260- 9267, Jul. 2009.

[2] J. B. Jiao, Q. X. Ye, and Q. M. Huang, "A configurable method for multistyle license plate recognition," Pattern Recognit., vol. 42, no. 3, pp. 358-369, Mar. 2009.

[3] H. Caner, H. S. Gecim, and A. Z. Alkar, "Efficient embedded neural network- based license plate recognition system," IEEE Trans. Veh. Technol., vol. 57, no. 5, pp. 2675-2683, Sep. 2008.

[4] C. Anagnostopoulos, I. Anagnostopoulos, V. Loumos, and E. Kayafas, "A license plate-recognition algorithm for intelligent transportation system applications," IEEE Trans. Intell. Transp. Syst., vol. 7, no. 3, pp. 377-392, Sep. 2006.

[5] S. L. Chang, L. S. Chen, Y. C. Chung, and S.W. Chen, "Automatic license plate recognition," IEEE Trans. Intell. Transp. Syst., vol. 5, no. 1, pp. 42- 52, Mar. 2004.

[6] V. Shapiro, G. Gluhchev, and D. Dimov, "Towards a multinational car license plate recognition system," Mach. Vis. Appl., vol. 17, no. 3, pp. 173-183, Aug. 2006.

[7] G.Sun, G.Li, L.Xu and J.Wang, "The Location and Recognition of Chinese Vehicle License Plates under Complex Backgrounds," Journal of Multimedia., vol. 4, no.6, pp.442-449 Dec 2009.

[8] A.Tihar, A.Adnan, M.Fahad "License Plate Recognition for Pakistani License plates", Canadian journal on image processing., vol. 1, no.2, April 2010.

[9] L.jin, H.Xian, j.Bie, Y.Sun, H.Hou "Building license plate recognition systems", Sensors 2012, vol.12, June 2012.

[10] Y.Wen, Y.Lu, J.Yan, Z.Zhou, K.M.von Deneen, and P.Shi, "An Algorithm for license Plate Recognition Applied to intelligent Transportation system," IEEE Trans.Intell.Transp.Syst., vol. 12, no.3, pp. 830-845, Sept- 2011

[11] T.D.Duan, T.L.Houng, T.V.Phuoc, N.V.Hoang "License Plate Recognition Algorithm for Passenger Cars in Chinese Residential Areas", Int.Conf of Computer Science, Feb2005

[12] D. N. Zheng, Y. N. Zhao, and J. X. Wang, "An efficient method of license plate location," Pattern Recognit. Lett., vol. 26, no. 15, pp. 2431-2438, Nov. 2005. 
[13] V. Abolghasemi and A. Ahmadyfard, "An edge-based color-aided method for license plate detection," Image Vis. Comput., vol. 27, no. 8, pp. 1134-1142, Jul. 2009.

[14] Z. G. Xu and H. L. Zhu, "An efficient method of locating vehicle license plate," in Proc. 3rd ICNC, 2007, pp. 180183.

[15] H. F. Zhang, W. J. Jia, X. J. He, and Q. Wu, "A fast algorithm for license plate detection in various conditions," in Proc. IEEE Int. Conf. Syst., Man, Cybern., Oct. 8-11, 2006, vol. 3, pp. 2420-2425.

[16] W. J. Jia, H. F. Zhang, and X. J. He, "Region-based license plate detection," J. Netw. Comput. Appl., vol. 30, no. 4, pp. 1324-1333, Nov. 2007.

[17] K.Deb, H.Chae, K.Jo, "Vehicle license plate detection method based on sliding concentric windows and histogram," Journal of computers, vol.4, no. 8, pp.771-777, Aug 2009.
[18] M.F.Zakaria, S.A.Suandi, "Malaysian car number plate Detection System based on template matching and colour information," IJCSE, vol.02 no.04,pp. 1159-1164 Jan 2010

[19] S.Saha, S.Basu, M.Nasipuri, D.K.Basu, "License plate Localization from vehicle images:An edge based multistage Approach," ACEEE ,vol 1, no.1, pp.284-288,May 2009.

[20] Y.Qui, M.Sun, W.Zhou, "License plate extraction based on vertical edge detection and mathematical morphology," IEEE, Feb 2009.

[21] Y.Wen, Y.Lu, J.Yan, Z.Zhou, K.M.von Deneen, and P.Shi, "An Algorithm for license Plate Recognition Applied to intelligent Transportation system," IEEE Trans.Intell.Transp.Syst., vol. 12, no.3, pp. 830-845, Sept- 2011

Table 1. Comparison of LPR systems

\begin{tabular}{|c|c|c|c|c|c|c|}
\hline $\begin{array}{l}\text { Ref: } \\
\text { No }\end{array}$ & $\begin{array}{l}\text { LPD (Success } \\
\text { Rate \%) }\end{array}$ & $\begin{array}{c}\text { CR Method } \\
\text { (Success Rate \%) }\end{array}$ & $\begin{array}{l}\text { Environment } \\
\text { Conditions }\end{array}$ & $\begin{array}{c}\text { Tilt } \\
\text { Correction }\end{array}$ & $\begin{array}{l}\text { Recognized } \\
\text { Character }\end{array}$ & $\begin{array}{l}\text { Rate } \\
(\%)\end{array}$ \\
\hline$[1]$ & $\begin{array}{l}\text { Search Window } \\
\text { Method (96.7) }\end{array}$ & $\begin{array}{ll}\text { Artificial } & \text { Neural } \\
\text { Network } & (97.1)\end{array}$ & Controlled & No & $\begin{array}{l}\text { English } \\
\text { Numerals }\end{array}$ & 93.9 \\
\hline [2] & $\begin{array}{c}\text { Edge Analysis } \\
(95.9)\end{array}$ & $\begin{array}{l}\text { Artificial Neural } \\
\text { Network } \\
(92.3)\end{array}$ & Controlled & Yes & $\begin{array}{l}\text { Chinese } \\
\text { English } \\
\text { Numeral }\end{array}$ & 90.1 \\
\hline [3] & CCA (91.7) & $\begin{array}{c}\text { SO Neural Network } \\
(87.16)\end{array}$ & Controlled & No & $\begin{array}{l}\text { English } \\
\text { Numeral }\end{array}$ & 90.93 \\
\hline [4] & SCW (96.5) & PNN (89.1) & Controlled & No & $\begin{array}{l}\text { English } \\
\text { Numeral }\end{array}$ & 86.0 \\
\hline [5] & $\begin{array}{l}\text { Fuzzy Discipline } \\
(97.9)\end{array}$ & $\begin{array}{c}\text { SO } \\
\text { Neural Network } \\
(95.6)\end{array}$ & Less Controlled & No & $\begin{array}{l}\text { English } \\
\text { Numeral }\end{array}$ & 93.7 \\
\hline [10] & $\begin{array}{l}\text { Improved Bernsen } \\
(97.16)\end{array}$ & $\begin{array}{ll}\text { SVM } & (97.8)\end{array}$ & Uncontrolled & Yes & $\begin{array}{l}\text { Chinese English } \\
\text { Kana, Numeral }\end{array}$ & 93.54 \\
\hline [8] & $\begin{array}{l}\text { Vertical Edge } \\
\text { Detection }(92.5)\end{array}$ & $\begin{array}{c}\text { Template matching } \\
(91.1)\end{array}$ & Controlled & No & $\begin{array}{c}\text { English } \\
\text { Numerals }\end{array}$ & 92.1 \\
\hline [9] & $\begin{array}{l}\text { Hough Transform } \\
\text { + Counter } \\
\text { algorithm (98.76) }\end{array}$ & $\begin{array}{l}\text { Hidden Markov } \\
\text { Model }\end{array}$ & Controlled & No & $\begin{array}{l}\text { English } \\
\text { Numerals }\end{array}$ & 92.85 \\
\hline
\end{tabular}

Table 2 Comparison of LPD Systems

\begin{tabular}{|c|c|l|l|c|c|c|}
\hline $\begin{array}{c}\text { Ref } \\
\text { No: }\end{array}$ & LPD Method & \multicolumn{1}{|c|}{ Merits } & Demerits & $\begin{array}{c}\text { Color } \\
\text { Analysis } \\
\text { plate }\end{array}$ & $\begin{array}{c}\text { Image } \\
\text { Enhancem } \\
\text { ent }\end{array}$ & Rate (\%) \\
\hline$[12]$ & $\begin{array}{c}\text { Vertical Edge } \\
\text { extraction }\end{array}$ & simple method & $\begin{array}{l}\text { image enhancement will } \\
\text { not work properly in } \\
\text { severe illumination } \\
\text { conditions, } \\
\text { slowest method }\end{array}$ & No & Yes & 99.7 \\
\hline$[13]$ & $\begin{array}{l}\text { Edge detection } \\
\text { low quality images are } \\
\text { taken for study }\end{array}$ & $\begin{array}{l}\text { when the angle between } \\
\text { camera and plate } \\
\text { increases system fails }\end{array}$ & Yes & Yes & - \\
\hline$[14]$ & $\begin{array}{c}\text { Corner } \\
\text { detection } \\
\text { method }\end{array}$ & $\begin{array}{l}\text { efficient and robust } \\
\text { method }\end{array}$ & $\begin{array}{l}\text { Failure occur due to the } \\
\text { if the images are taken } \\
\text { in the caliginous }\end{array}$ & No & Yes & 95.9 \\
\hline
\end{tabular}




\begin{tabular}{|c|c|c|c|c|c|c|}
\hline & & & $\begin{array}{l}\text { surroundings and } \\
\text { images will be fuzzy } \\
\text { due to the environment } \\
\text { conditions }\end{array}$ & & & \\
\hline [15] & $\begin{array}{l}\text { Adaboost } \\
\text { algorithm }\end{array}$ & $\begin{array}{l}\text { detect license plate from } \\
\text { complex background }\end{array}$ & $\begin{array}{l}\text { when the scaling factor } \\
\text { increases, detection rate } \\
\text { decreases }\end{array}$ & No & No & 96.4 \\
\hline [16] & $\begin{array}{l}\text { Region-based } \\
\text { method }\end{array}$ & $\begin{array}{l}\text { robustness to } \\
\text { interference characters } \\
\text { that cause detection } \\
\text { error }\end{array}$ & $\begin{array}{l}\text { detect correctly only if } \\
\text { the background color of } \\
\text { license plate is differnt } \\
\text { from the vehicle body }\end{array}$ & No & No & 97.4 \\
\hline [17] & $\begin{array}{l}\text { Sliding } \\
\text { concentric } \\
\text { window }\end{array}$ & $\begin{array}{l}\text { Method is used to speed } \\
\text { up the detection rate }\end{array}$ & $\begin{array}{l}\text { Sensitive to angle of } \\
\text { view, physical } \\
\text { appearance and } \\
\text { environment conditions }\end{array}$ & Yes & No & 82.5 \\
\hline [18] & $\begin{array}{l}\text { Template } \\
\text { matching }\end{array}$ & $\begin{array}{l}\text { Low complexity, Low } \\
\text { processing time }\end{array}$ & $\begin{array}{l}\text { Car grill or } \\
\text { manufacturer logo, } \\
\text { number plate intensity } \\
\text { not same:-all leads to } \\
\text { detection failure. }\end{array}$ & Yes & Yes & $88.7 \%$ \\
\hline [19] & $\begin{array}{l}\text { Edge-based } \\
\text { multi stage } \\
\text { approach }\end{array}$ & $\begin{array}{l}\text { Mainly applied to our } \\
\text { Indian vehicles }\end{array}$ & $\begin{array}{l}\text { Performs well only for } \\
\text { less noisy images }\end{array}$ & No & Yes & 89.2 \\
\hline [20] & $\begin{array}{l}\text { Vertical edge } \\
\text { detection and } \\
\text { MM }\end{array}$ & $\begin{array}{l}\text { Plate extraction done in } \\
\text { complex background, } \\
\text { distance between camera } \\
\text { and car is not fixed. }\end{array}$ & $\begin{array}{l}\text { Fails due to the similar } \\
\text { region with characters } \\
\text { to the license plate. }\end{array}$ & No & Yes & 98.1 \\
\hline [21] & $\begin{array}{c}\text { Improved } \\
\text { Bernsen and } \\
\text { CCA }\end{array}$ & $\begin{array}{l}\text { Simple method and non- } \\
\text { license plate are } \\
\text { effectively filtered, } \\
\text { insensitive to brightness, } \\
\text { effectively removes the } \\
\text { shadows in the image. }\end{array}$ & $\begin{array}{l}\text { Not good for license } \\
\text { plate with only one } \\
\text { large numeral and no } \\
\text { frame }\end{array}$ & No & Yes & 97.16 \\
\hline
\end{tabular}

